\title{
EFFICACY OF RECIPROC AND MANUAL TECHNIQUES WITH AND WITHOUT SOLVENT IN REMOVING DIFFERENT OBTURATING SYSTEMS
}

\author{
Amr M. Eldemerdash *, Hayam Y. Hassan ** and Salma H. Al Ashry ***
}

\begin{abstract}
The Aim: of this study is to evaluate the efficacy of Reciproc and manual techniques with and without solvent for removing Real-Seal obturating system and Gutta-percha with resin sealer using Stereomicroscope. Methods: Eighty extracted mandibular premolars having single root canal were distributed into two groups stated on the obturation systems (Real-Seal obturating system and Guttapercha with resin sealer) used. Then subdivided into two subgroups according to the method of obturating material removal (Reciproc and manual technique). Further subdivided into two classes by using solvent or not. Roots were separated in bacco-lingual direction into two equal halves then analyzed using Stereomicroscope at the cervical, middle and apical parts. Results: Reciproc system as retreatment instrument give the best result than manual instruments in removing both obturating material used (Real-Seal system and Gutta-Percha) and this was statistically significant. Without using solvent give the best result than using solvent in removing both obturating material used (Real-Seal system and Gutta-Percha) and this was statistically significant. Apical region recorded highest debris mean value followed by middle region while the lowest mean value recorded cervically and this was statistically significant. Conclusion: Reciproc system was more effective than manual instruments in removal of root canal obturating materials for endodontic retreatment.
\end{abstract}

Keywords: Reciproc, Real-Seal, Retreatment, Stereomicroscope.

\section{INTRODUCTION}

Success of root canal treatment is adequate obturation for the root canal space. The success of a clean, well-shaped root canal system compromises if the root canal may be poorly obturated ${ }^{(1)}$. The term "monoblock" become frequent in the endodontic literatures with the request of dentin adhesive technology in endodontics ${ }^{(2)}$.

Root canal treatment usually fails when treatment have shortage of acceptable standard. Therefore, nonsurgical root canal retreatment is indicated to perform effective cleaning, disinfection and proper root canal obturation ${ }^{(3)}$.

\footnotetext{
* Resident Dentist in Endodontic Department, Faculty of Dentistry, Suez Canal University, Ismailia, Egypt. ** Associate Professor of Endodontic, Faculty of Dentistry, Suez Canal University, Ismailia, Egypt.

*** Professor of Endodontic, Faculty of Dentistry, Ain Shams University, Cairo, Egypt.
} 
Regaining access to the root canal system through removal of the original root canal filling thus allowing supplementary cleaning and reobturation. Removal of obturating materials becomes an essential step to obtain access to the root canal system, debride necrotic tissue debris, bacteria and infected dentin ${ }^{(4)}$.

In response to the shortcomings of gutta-percha and sealers, Epiphany resin endodontic obturating system has introduced. Epiphany is able to make monoblock inside the canal space, where the Real-Seal core bonded to the Epiphany sealer, the resulting compound bonded to the dentine by the resin-based primer ${ }^{(5)}$.

Many systems were designed mainly for root canal cleaning and shaping others newly introduced instruments were particularly manufactured for removing root obturating material. The instruments used for retreatment must be efficient in removing root obturating material within less time required for removing it with manual procedures ${ }^{(6)}$.

Several instruments can be used to remove the root obturating material from the root canal, as well as the use of stainless steel H-files Gates-Glidden drills, nickel-titanium (NiTi) rotary instruments, ultrasonic instruments heat-bearing instruments lasers and use of solvents. Gutta-percha removal using rotary instruments in the retreatment process have decreased the chair-side clinical time ${ }^{(7)}$.

Reciproc system have an s-shaped cross-section, with two cutting blades, in a continuous taper over the first $3 \mathrm{~mm}$ of the file followed by a decreasing taper to the shaft ${ }^{(8)}$.

Solvent sometimes enabling the removal of gutta-percha by softening it. Chloroform is the most usually used solvent because of its efficiency. On the other hand, chloroform is considered safe if used carefully in a clinical precise manner. Another limitation is that chloroform leaves a fine layer or film of softened gutta-percha ${ }^{(9)}$.
This study evaluated the efficacy of Reciproc and manual techniques with and without solvent for removing Real-Seal obturating system and Guttapercha with resin sealer using Stereomicroscope.

\section{METHOD}

Eighty recently extracted sound permanent single-rooted mandibular premolars teeth were collected, cleaned and stored. Crowns of all teeth were cut with a diamond disk and the root length was standardized to approximately $17 \mathrm{~mm}$. Working length was determined by using k-file \#10 visually at one $\mathrm{mm}$ of the apical foramen.

\section{Root canal preparation}

The root canals of all teeth were prepared with Gates-Glidden drills size 4, 3 and 2 was used to prepare the cervical and middle regions of the root canal. The apical regions were prepared till $\mathrm{k}$-file size 40 using the balanced force technique. Irrigation was done with $1 \mathrm{ml}$ of freshly prepared $1.3 \%$ sodium hypochlorite after each file, followed by a flush of $5 \mathrm{ml}$ of $17 \%$ EDTA for $1 \mathrm{~min}$ to remove the smear layer.

\section{Grouping of samples}

The 80 specimens were divided into 2 equal main groups $(\mathrm{n}=40)$ according to obturating material. Group A: the root canals were obturated using Real-Seal obturating system (Sybronendo, West collins Avenue, Orange, CA U.S.A) according to manufacturer's instructions. Group B: the root canals were obturated using gutta percha points with ADSEAL resin sealer (Meta Biomed, Cheongju, South Korea) according to manufacturer's instructions.

Then each group was subdivided into two subgroups $(n=20)$ according to the method of obturating material removal. The first subgroup of each group $A_{1} \& B_{1}$ the obturating material was removed using Reciproc file \#40 (VDW, GmbH, 
Munich, Germany). The second subgroup of each group $\mathrm{A}_{2} \& \mathrm{~B}_{2}$ the obturating material was removed using Gates Glidden \# 4, 3, 2 \& H-file\#40.

Then, each subgroup subdivided into two classes $(n=10)$ : The first class of each subgroup $\left(\mathrm{A}_{1} \mathrm{a}, \mathrm{A}_{2} \mathrm{a}\right.$, $\left.\mathrm{B}_{1} \mathrm{a} \& \mathrm{~B}_{2} \mathrm{a}\right)$ the obturating material was removed using the removal in-combination with chloroform (ADWIC, Com. Qaliubiya, Egypt) as a solvent. The second class of each subgroup $\left(\mathrm{A}_{1 \mathrm{~b}}, \mathrm{~A}_{2 \mathrm{~b}}, \mathrm{~B}_{1 \mathrm{~b}}\right.$ \& $\mathrm{B}_{2 \mathrm{~b}}$ ) the obturating material was removed using the removal systems without using any solvent.

\section{Retreatment technique}

The first subgroup of each group $A_{1} \& B_{1}$ the obturating material was removed using Reciproc file \#40, .06 taper. The instrument advanced inside the root canal until removal of the obturating material to the full working length. The Reciproc instrument designed for single use, and it was used only in one root canal and was then discarded.

The second subgroup of each group $\mathrm{A}_{2} \& \mathrm{~B}_{2}$ the obturating material was removed from the coronal and middle regions using Gates-Glidden \# 4, 3, 2 at speed $1000 \mathrm{rpm}$ of micro motor machine followed by Hedstrom files (H-file) for the apical third with sizes $25,30,35,40$ in a circumferential quarter-turn push pull filing motion to remove obturating materials from the canal until the full working length.

The first class of each subgroup $\left(\mathrm{A}_{1 \mathrm{a}}, \mathrm{A}_{2 \mathrm{a}}, \mathrm{B}_{1 \mathrm{a}}\right.$ \& $\mathrm{B}_{2 \mathrm{a}}$ ) the obturating material were removed using the removal systems as mentioned before incombination with chloroform as a solvent. Few drops $(0.1 \mathrm{ml})$ of solvent (chloroform) were placed on obturation material to soften the material.

The second class of each subgroup $\left(\mathrm{A}_{1 \mathrm{~b}}, \mathrm{~A}_{2 \mathrm{~b}}, \mathrm{~B}_{1 \mathrm{~b}}\right.$ $\left.\& \mathrm{~B}_{2 \mathrm{~b}}\right)$ the obturating material was removed using the removal systems as mentioned before without using any solvent.

During re-instrumentation, each canal was irrigated with $1 \mathrm{ml}$ of freshly prepared $1.3 \%$ sodium hypochlorite after each file used.
All instruments were cleaned frequently and preparation was completed when there was no root obturating material covering the instruments. In addition, when the irrigating solution seemed clear of debris.

\section{Stereomicroscopic evaluation of the canal walls cleanliness:}

Cleanliness of the root canals after removal of obturating material was evaluated using Stereomicroscope (Scope capture, China). Grooves parallel to the long axis were made on the buccal and lingual surfaces of all the teeth and were cut into two halves using diamond disks then splitting completed using chisel. The canal was evaluated cervical, middle, and apical regions from coronal to apical.

The total areas of each third was determined, and the percentage of the area covered by filling debris was calculated. Images of each section were made by USB Stereomicroscope attached to IBM computer at the X30 magnification to allow complete visualization of canals. The debris present in the canals was outlined. Image $\mathbf{J}$ software (National Institutes of Health, v1.39a) was used to calculate the surface area of the root canal third and the debris present. This data was used to calculate a cleanliness percentage for each canal third as shown in Fig. (1).

\section{RESULTS}

The recorded data of remnants of the root obturating materials were tabulated and statistically analyzed using Friedman two-way ANOVA test $(\mathrm{P} \leq 0.05)$. Which was applied to investigate the main difference between groups. LSD (Least Square Difference) which was used to distinguish each group from others (Mean $\pm \mathrm{SD}$ ) measured in (pixels \%) the radicular regions in cervical, middle and apical regions. 


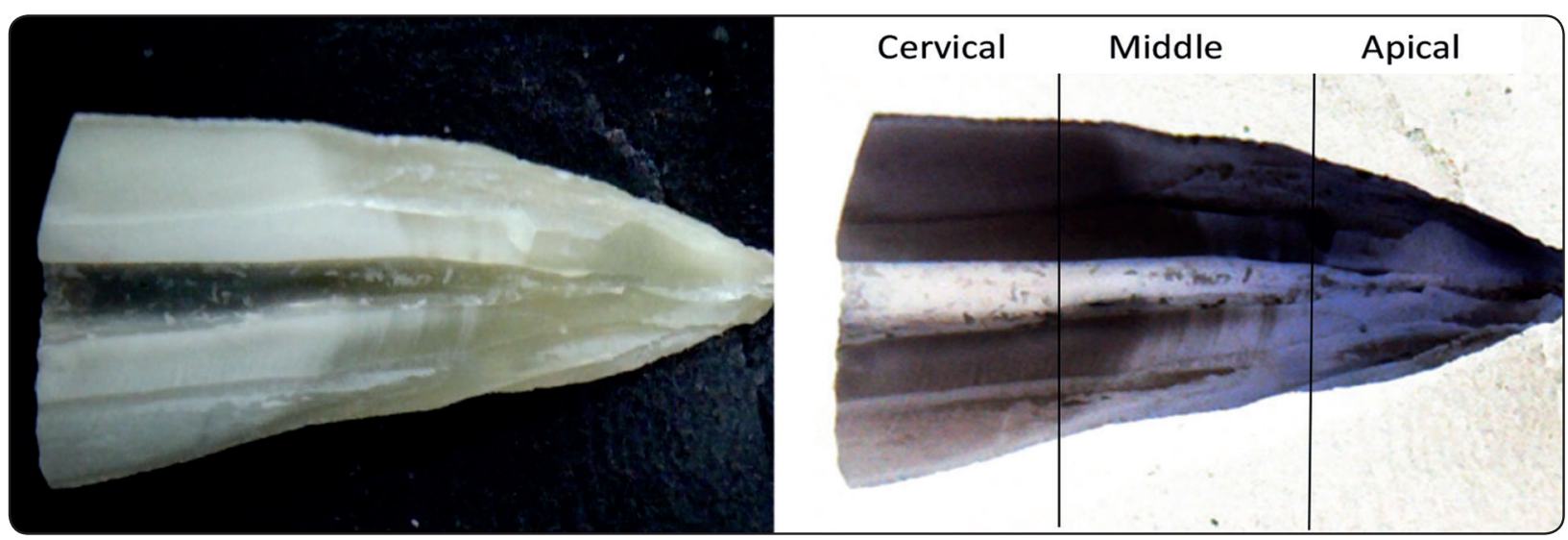

Fig. (1) Representative stereoscopic photographs (X 30) showing remnant distribution over root canal surface.

Comparison of remnant mean values percentage of two obturating systems removed by Reciproc with or without solvent at cervical, middle and apical regions, as demonstrated in table (1) and Fig. (2).

Real-Seal obturating system with solvent at the cervical region recorded lower remnant mean value percentage $\left(\mathrm{A}_{1 \mathrm{a}}\right)$ than without solvent $\left(\mathrm{A}_{1 \mathrm{~b}}\right)$ with no statistically significant difference. Although, at the middle and apical regions, it recorded higher remnant mean value percentage $\left(\mathrm{A}_{1 \mathrm{a}}\right)$ than without solvent $\left(\mathrm{A}_{1 \mathrm{~b}}\right)$. There was no statistically significant difference at the middle. While, there was a statistically significant difference at the apical.

Gutta-percha obturating system with solvent at the cervical, middle and apical regions recorded higher remnant mean value percentage $\left(\mathrm{B}_{1 \mathrm{a}}\right)$ than without solvent $\left(\mathrm{B}_{1 \mathrm{~b}}\right)$ with statistically significant difference.
Comparison of remnant mean values percentage of two obturating systems removed by manual instrument with or without solvent at cervical, middle and apical regions, as demonstrated in table (2) and Fig. (3).

Real-Seal obturating system with solvent at the cervical, middle and apical regions, recorded higher remnant mean value percentage $\left(\mathrm{A}_{2 \mathrm{a}}\right)$ than without solvent $\left(\mathrm{A}_{2 \mathrm{~b}}\right)$. With statistically significant difference at cervical and middle. While, there was no statistically significant difference at the apical.

Gutta-percha obturating system with solvent at the cervical, middle and apical regions recorded higher remnant mean value percentage $\left(\mathrm{B}_{2 \mathrm{a}}\right)$ than without solvent $\left(\mathrm{B}_{2 \mathrm{~b}}\right)$ with statistically significant difference.

TABLE (1) Comparison between values removed by Reciproc with or without solvent at cervical, middle and apical regions

\begin{tabular}{|c|c|c|c|c|c|c|c|}
\cline { 3 - 8 } \multicolumn{2}{c|}{} & \multicolumn{4}{c|}{ Real-Seal } & \multicolumn{3}{c|}{ Gutta-percha } \\
\cline { 3 - 9 } \multicolumn{2}{c|}{} & Cervical & Middle & Apical & Cervical & Middle & Apical \\
\hline \multirow{3}{*}{ Solvent } & With & $9.18 \pm 1.3$ & $11.22 \pm 1.5$ & $20.03 \pm 4.8$ & $18.5 \pm 3.2$ & $19.58 \pm 4.3$ & $27.50 \pm 4.6$ \\
\cline { 2 - 9 } & Without & $11.12 \pm 1.9$ & $10.14 \pm 2.1$ & $13.62 \pm 2.5$ & $5.53 \pm 1.2$ & $12.12 \pm 2.4$ & $12.36 \pm 2.9$ \\
\hline \multirow{2}{*}{ t-test } & P value & 0.286 & 0.324 & $0.047 *$ & $0.00042 *$ & $0.01272 *$ & $0.0001 *$ \\
\hline
\end{tabular}




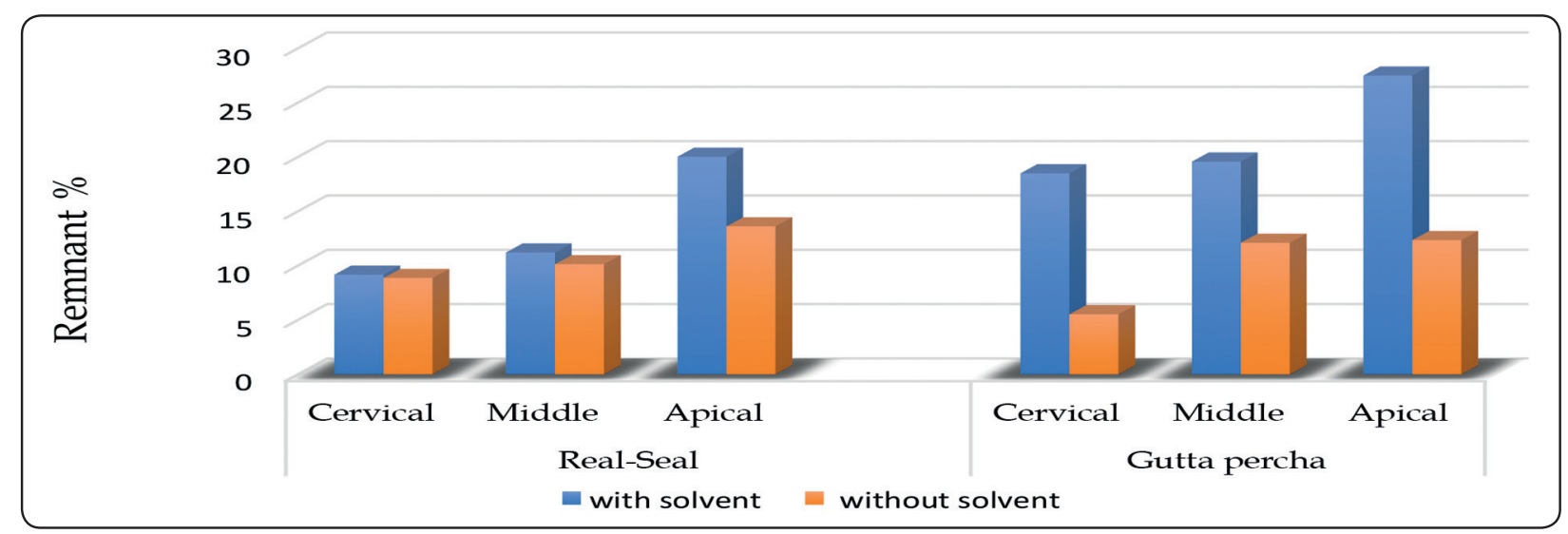

Fig. (2) Comparison between values removed by Reciproc with or without solvent at cervical, middle and apical regions

TABLE (2) Comparison between values removed by manual instrument with or without solvent at cervical, middle and apical regions.

\begin{tabular}{|c|c|c|c|c|c|c|c|}
\hline \multirow{2}{*}{} & \multicolumn{3}{|c|}{ Real-Seal } & \multicolumn{3}{c|}{ Gutta- percha } \\
\cline { 3 - 9 } & Cervical & Middle & Apical & Cervical & Middle & Apical \\
\hline \multirow{3}{*}{ Solvent } & With & $20.18 \pm 4.1$ & $20.46 \pm 3.8$ & $25.39 \pm 4.9$ & $23.09 \pm 4.8$ & $53.28 \pm 10.4$ & $59.09 \pm 11.2$ \\
\cline { 2 - 8 } & Without & $11.12 \pm 1.9$ & $14.75 \pm 2.7$ & $22.55 \pm 4.6$ & $13.86 \pm 1.2$ & $17.94 \pm 3.3$ & $22.62 \pm 4.9$ \\
\hline \multirow{2}{*}{ t-test } & P value & $0.0001^{*}$ & $0.023^{*}$ & 0.147 & $0.0001^{*}$ & $0.0001^{*}$ & $0.0001^{*}$ \\
\hline
\end{tabular}

ns; non-significant $(p>0.05) \quad$ *; significant $(p<0.05)$

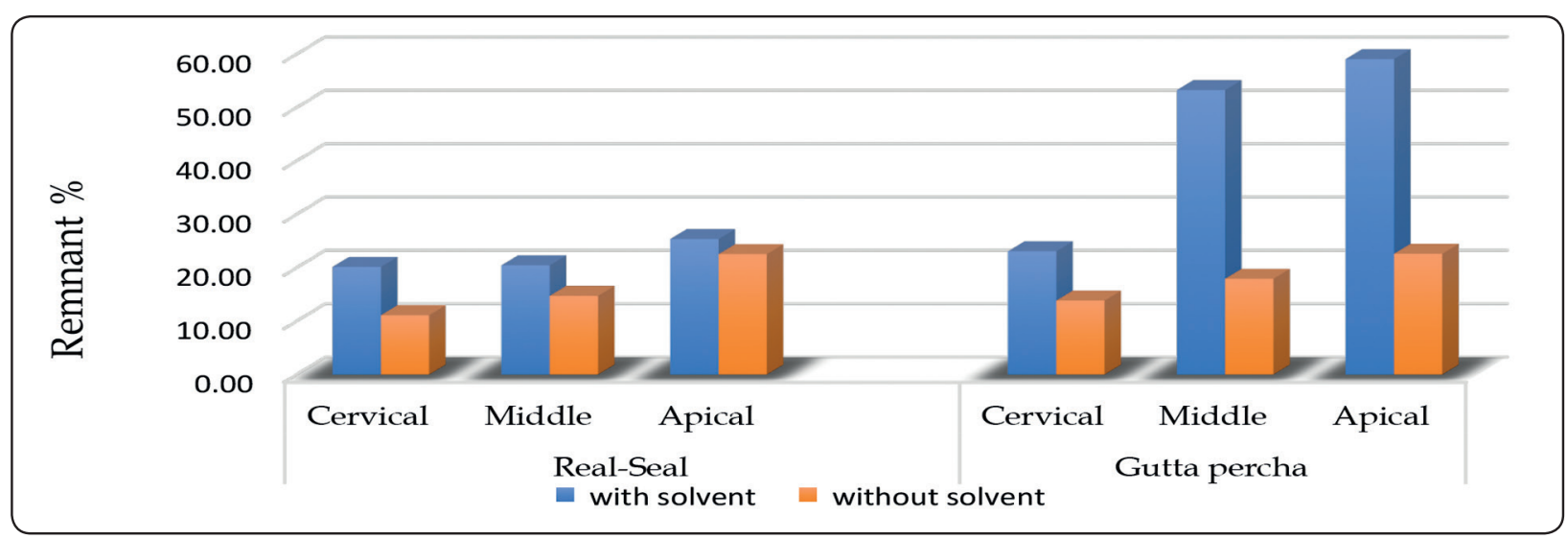

Fig. (3) Comparison between values removed by manual instrument with or without solvent at cervical, middle and apical regions. 


\section{DISCUSSION}

Success of root canal treatment is to adequately obturate the prepared root canal. Gutta-percha commonly accepted as the gold standard root obturating material. Used in many forms in practice, with various obturating techniques and combined with many types of sealers ${ }^{(10)}$.

The nonsurgical root canal retreatment is the preferred treatment option after a defective endodontic therapy to improve root canal disinfection, debridement and obturation. During retreatment, residual gutta-percha and sealer remains in the root canal. Increase the potential micro-organism load and affect quality of new root canal obturation ${ }^{(11)}$.

In the current study, Reciproc system used for root canal treatment using motor-driven $\mathrm{NiTi}$ instrument. These instruments are manufactured from M-wire NiTi alloy, which provide greater resistance to cyclic fatigue and greater flexibility than the conventional NiTi instruments. On the other hand, the Reciproc system not mainly designed for root canal retreatment but the specific design of the instruments, in addition to reciprocating motion, can be potentially beneficial for the efficient obturatig material removal ${ }^{(12)}$.

In the current study, with application of solvent regardless to obturation materials or radicular region, manual instruments statistically significant higher remnant mean value than Reciproc system. This may be attributed that Reciproc system has a varying taper along the shaft. That with the reciprocating movement can partly explain the improvement of Reciproc system in the removal of root obturating materials. This improved by Zuolo et al (3), Mollo et al ${ }^{(13)}$, Joseph et $\mathrm{al}^{(14)}$ and Fariniuk et al ${ }^{(15)}$

In our study, apical region recorded highest remnant mean value followed by middle region while the lowest mean value recorded cervically, and this was statistically significant. This may be due to that the apical portion is the narrowest and deepest part of the canal and the most difficult area to be reached with instruments and irrigating solutions and during instrumentation the remnants and debris pushed and accumulated apically. This was in agreement with Schirrmeister et al ${ }^{(16)}$.

In our study, regardless to obturating material or instrument or region, chloroform when used as a solvent showed less efficacy than without using it and this is was statistically significant. This may be due to the solvents ability to soften obturation materials and modify its structure to a viscous and highly adhesive material resulted in a filmy appearance on the canal walls and compacted into dentinal tubules. That makes it more difficult to remove. So using solvents seems to complicate rather than facilitate the filling removal ${ }^{(43)}$. This was agreed with, Kfir et al ${ }^{(6)}$ Das et al ${ }^{(17)}$ Bhagavaldas et al $^{(18)}$ and Dadresanfar et al ${ }^{(\mathbf{1 9})}$.

\section{CONCLUSION}

Reciproc system as retreatment instrument give the best result than manual instruments in removing both obturating material used (Real-Seal system \& Gutta-Percha) and this was statistically significant.

Without using solvent give the best result than using solvent in removing both obturating material used (Real-Seal system \& Gutta-Percha) and this was statistically significant.

Apical region recorded highest debris mean value followed by middle region while the lowest mean value recorded cervically and this was statistically significant.

\section{REFERENCES}

1. Schafer E and Olthoff G.: Effect of three different sealers on the sealing ability of bothThermafil obturators and cold laterally compacted gutta-percha.J Endod. 2002, 28:423- 6 .

2. Tay FR and Pashley DH.: Monoblocks in root canals - a hypothetical or a tangible goal. J Endod. 2007, 33:391-8. 
3. Zuolo AS, Mello JE Jr, Cunha RS, Zuolo ML and Bueno CES.: Efficacy of reciprocating and rotary techniques for removing filling material during root canal retreatment. Int Endod J. 2013, 46: 947-53.

4. Kanaparthy A and Kanaparthy R.: The comparative efficacy of different files in the removal of different sealers in simulated root canal retreatment- An In-vitro Study. J Clin Diagn Res. 2016, 10:130-3.

5. Hassanloo A, Watson $\mathrm{P}$, Finer $\mathrm{Y}$ and Friedman S.: Retreatment efficacy of the Epiphany soft resin obturation system. Int Endod J. 2007, 40:633-43.

6. Kfir A, Tsesis I, Yakirevich E, Matalon S and Abramovitz I.: The efficacy of five techniques for removing root filling material: microscopic versus radiographic evaluation. Int Endod J. 2012, 45: 35-41.

7. Khedmat S, Azari A, Shamshiri AR, Fadae M and Bashizadeh Fakhar H.: Efficacy of ProTaper and Mtwo Retreatment Files in Removal of Gutta-percha and GuttaFlow from Root Canals. Iran Endod J. 2016, 11:1847.

8. Capar ID, Arslan H, Ertas H, Geok T and Saygili G.: Effectiveness of ProTaper Universal retreatment instruments used with rotary or reciprocating adaptive motion in the removal of root canal filling material. Int Endod J. 2015, 48: 79-83.

9. Takahashi CM, Cunha RS, de Martin AS, Fontana CE, Silveira CF and da silveira Bueno CE.: In vitro evaluation of the affectiveness of ProTaper universal rotary retreatment system for gutta-percha removal with or without a solvent. J Endod. 2009, 11: 1580-3

10. Patel DV, Sherriff M, Ford TR, Watson TF and Mannocci F.: The penetration of RealSeal primer and Tubliseal into root canal dentinal tubules: a confocal microscopic study. Int Endod J. 2007, 40:67-71.

11. Ozyurek $\mathrm{T}$ and Ozsezer-Demiryurek E.: Efficacy of protaper next and protaper universal retreatment systems in removing gutta-percha in curved root canals during root canal retreatment. J Istanb Univ Fac Dent. 2017, 51:7-13.

12. De Souza PF, Oliveira Goncalves LC, Franco Marques
AA, Sponchiado Junior EC, Roberti Garcia Lda F and de Carvalho FM.: Root canal retreatment using reciprocating and continuous rotary nickel-titanium instruments., Eur J Dent. 2015, 9:234-9.

13. Mollo A, Botti G, Prinicipi Goldoni N, Randellini E, Paragliola R, Chazine M, Ounsi HF and Grandini S.: Efficacy of two Ni-Ti systems and hand files for removing gutta-percha from root canals. Int Endod J. 2012, 45:1-6.

14. Joseph M, Ahlawat J, Malhotra A, Rao M, Sharma A and Talwar S.: In vitro evaluation of efficacy of different rotary instrument systems for gutta percha removal during root canal retreatment. J Clin Exp Dent. 2016, 8:355-60.

15. Fariniuk LF, Azevedo MAD, Carneiro E, Westphalen VPD, Piasecki L and da Silva Neto UX.: Efficacy of protaper instruments during endodontic retreatment. Indian J Dent Res. 2017, 28:400-5.

16. Schirrmeister JF, Meyer KM, Hermanns P, Altenburger MJ and Wrbas KT.: Effectiveness of hand and rotary instrumentation for removing a new synthetic polymerbased root canal obturation 185 material (Epiphany) during retreatment. Int Endod J. 2006, 39, 150-56.

17. Das S, Ida AD, Das S, Nair V,Saha N, and Chattopadhyay S.: Comparative evaluation of three different rotary instrumentation systems for removal of gutta-percha from root canal during endodontic retreatment: An in vitro study.J Conserv Dent. 2017, 20: 311-16.

18. Bhagavaldas MC, Diwan A, Kusumvalli S, Pasha S, Devale $M$ and Chava DC.: Efficacy of two rotary retreatment systems in removing Gutta-percha and sealer during endodontic retreatment with or without solvent: A comparative in vitro study.J Conserv Dent. 2017, 20: 1216.

19. Dadresanfar B, Mehrvarzfar P, Saghiri MA, Ghafari S, Khalilak Z and Vatanpour M.: Efficacy of two rotary systems in removing gutta-percha and sealer from the root canal walls. Iran Endod J. 2011, 6:69-73. 